Submission ID: 43722

\title{
Seismogeological Model of the Structure of Riphean Deposits Within the
}

Kureyskaya Syneclise

S.V. Kotova* (SNIIGGiMS JSC), G.D. Uhlova (SNIIGGiMS JSC), A.N. Protsko (SNIIGGiMS JSC)

\section{SUMMARY}

A uniform network of regional composite surveyes for seismic profiles has been created. The main structura features of Riphean complex are considered. Three types of seismic recording are defined. The zone of lack of Riphean deposits is specified. The stratigraphic binding and correlation of the reflecting horizon R4 are performed. A structural-tectonic and predictive scheme of the pre-Vendian erosion surface was constructed. 


\title{
Сейсмогеологическая модель строения рифейских отложений в пределах Курейской синеклизы
}

\author{
С.В. Котова* (АО "СНИИГГиМС"), Г.Д. Ухлова (АО "СНИИГГиМС"), А.Н. Процко (АО \\ "СНИИГГиМС")
}

\section{Введение}

С целью изучения геологического строения рифейских отложений и определения перспективных направлений поиска месторождений УВ создана каркасная сеть региональных композитных маршрутов по сейсмическим профилям. Данная сеть является основой для сейсмогеологического моделирования строения региона. При составлении региональных маршрутов авторы придерживались соблюдения следующих условий: информативность временных разрезов; расположение составных профилей с максимальной близостью к скважинам; сеть маршрутов должна быть равномерной. С целью повышения геологической информативности материалов сейсморазведки была выполнена переобработка архивных данных и дообработка временных разрезов. Таким образом, на весь регион была составлена сеть из кинематически, и по возможности, динамически увязанных 63 маршрутов общей протяженностью свыше 28000 км (Исаев А.В. и др). Дополнительно проанализировано более 100000 пог. км архивных площадных сейсмических разрезов МОГТ-2D, а также информация по 2164 скважинам.

\section{Строение рифейских отложений}

В структуре рифейского комплекса отложений рассматриваемой территории следует выделять Приенисейский и Ангаро - Котуйский прогибы. Приенисейский прогиб является краевым для Сибирской платформы и разделяется на две обособленные по совокупности структурно вещественных характеристик "ячеи": Нижневельминско - Туруханскую на севере и Присаяно Тасеевскую на юге. Ангаро - Котуйский рифейский прогиб является внутриплатформенным. Прогиб начинается на юге от входящего (по Н.С. Шатскому) Иркенеевского угла западной границы Сибирской платформы и прослеживается на восток - северо - восток до Чадобецкого поднятия, затем его осевая часть поворачивает на север. Основная особенность строения Ангаро - Котуйского прогиба - различная дислоцированность западных и восточных краевых частей. Западная часть представляет собой зону, в пределах которой наблюдаются пликативные и дизъюнктивные дислокации значительной амплитуды. Дислоцированность восточного борта существенно слабее, что отражает ассиметрию в интенсивности позднерифейских тектонических движений. Для всех вышеперечисленных рифейских прогибов характерна большая мощность отложений и их синклинорное строение [Филипцов, 2011].

Наиболее полно рифейские отложения изучены в центральной части Байкитской антеклизы, известной как Юрубчено-Тохомская зонта (ЮТЗ) нефтегазонакопления, где сконцентрирована подавляющая часть параметрических и поисково-разведочных скважин. Изучение отложений рифея является основой для выделения новых перспективных зон для поиска залежей УВ в рифейском НГК.

\section{Оценка информативности временных разрезов для рифейского интервала разреза}

Основная сложность анализа фактических данных состоит в том, что весь сейсмический материал достаточно разнородный по качеству. Информативность временных разрезов сильно отличается. Поэтому первоначально ставилась задача визуальной отбраковки временных разрезов, не позволяющих выявить особенности строения рифейских отложений. Существует множество геологических факторов, осложняющих сейсмическую запись рифейского интервала разреза. К основным из них можно отнести:

- сложные поверхностные сейсмогеологические условия (появление на дневной поверхности нижнетриасовых грубообломочных образований);

- латеральную неоднородность среды, фациальные замещения глинистых отложений карбонатными, степень метаморфизма осадочных отложений. 
- блоковое строение и наличие тектонических нарушений с большой амплитудой смещения по вертикали, а также наличие внутририфейских несогласий.

- направление сейсмического профиля. Преимущественно наиболее информативные разрезы располагаются в субширотном направлении, вкрест простиранию основных структурных элементов [Филипцов, 2011].

По волновому полю рифейского интервала разреза можно выделить три основных типа записи, соответствующие различной информативности сейсмических разрезов (Рис. 1). Все выделенные типы носят условный характер. Поскольку в сложной сейсмогеологической обстановке, рядом расположенные профили могут резко отличаться по динамическим характеристикам.

тип 1: информативные сейсмические разрезы. Отражающие границы внутририфейского интервала являются протяженными и динамически выдержанными.

тип 2: сейсмические разрезы средней информативности. Характеризуется наличием не протяженных осей синфазности. Корреляция внутририфейских отражающих горизонтов неоднозначна в силу сложной картины волнового поля.

тип 3: неинформативные. Волновое поле представлено короткими отражениями, фиксируемыми на фоне хаотической формы записи. По данному типу сложно оценить кинематические особенности распределения внутририфейских

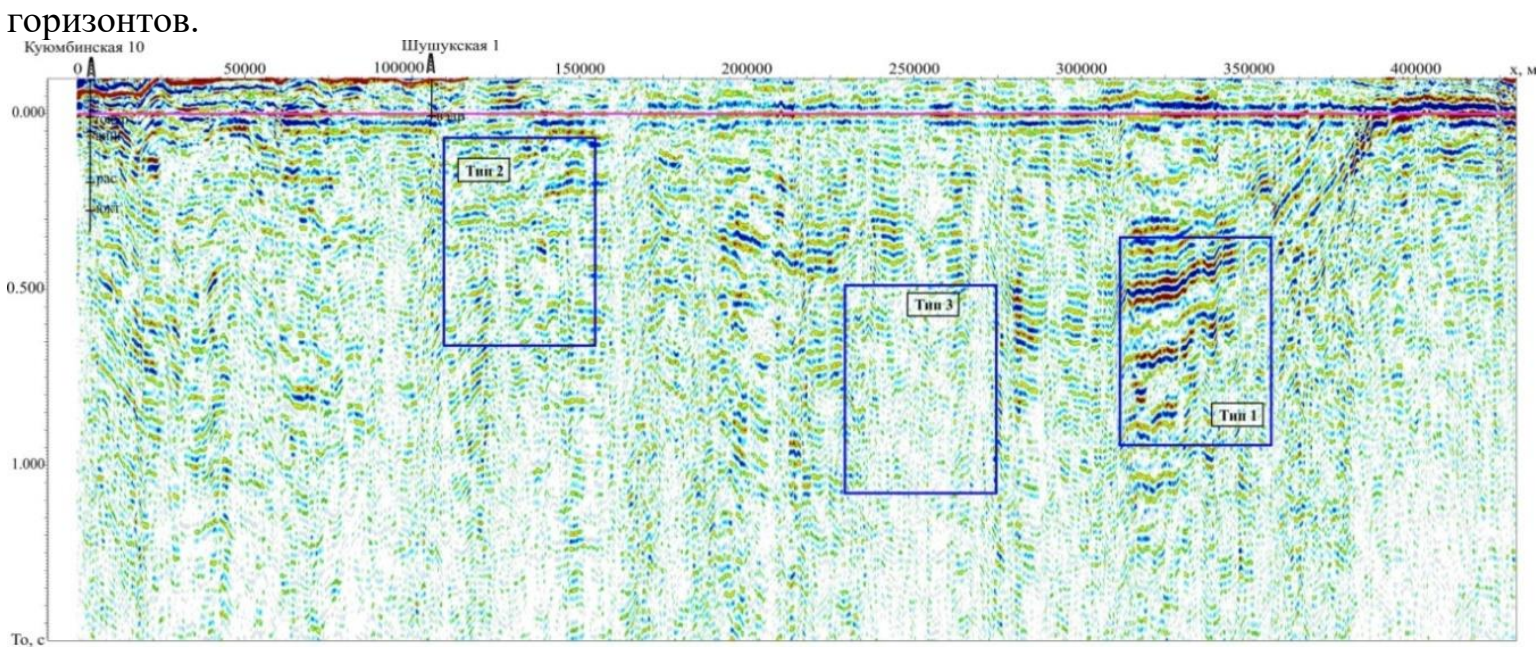

Рисунок 1 Типы сейсмической записи, характеризующие информативность волновой картины, в интервале, соответствующем рифейским отложениям

\section{Уточнение зоны отсутствия рифейских отложений}

По материалам бурения и сейсморазведочных работ центральную часть Сибирской платформы занимает обширная зона, где отсутствуют рифейские отложения. Она вытянута в субмеридианальном направлении с юга (от р. Ангары) на север (до р. Оленек). Крупные зоны отсутствия рифейских отложений установлены и в северо - западной части платформы [Мельников и др, 2005]. На выделение пространственных границ распространения рифейских образований существуют разные точки зрения. Зона отсутствия рифейских отложений, принятая авторами, уточнялась в связи с появившимися новыми данными по скважинам, а также предполагается на основании интерпретации сейсмических профилей МОГТ, где в достаточной мере фиксируется примыкание наклонных внутририфейских границ к поверхности фундамента, характеризующимся отсутствием регулярной сейсмической записи. Хотя соблюдение этого принципа происходит далеко не всегда. Отождествить сейсмическую запись, связанную с отложениями фундамента на практике оказывается весьма сложной задачей. Казалось бы, предположение о консолидированности фундамента должно исключить появление в его интервале отражающих площадок, но на временных разрезах они присутствуют практически повсеместно [Ефимов А.С, Смирнов М. Ю. и др, 2010], в том числе и за счет частично кратных волн. Таким образом, выделение зоны отсутствия рифейских 
отложений является достаточно сложным вопросом и при дальнейших исследованиях будет уточняться по мере появления новых данных о геологическом строении рифея.

\section{Стратиграфическая привязка и корреляция отражающих горизонтов}

Накопленный производственными и научными организациями опыт позволяет выделить в отложениях рифея до пяти отражающих горизонта (ОГ), основными из которых являются $\mathrm{R}_{4}$, $\mathrm{R}_{3}$ и $\mathrm{R}_{2}$. В данной работе рассмотрен только отражающий горизонт $\mathrm{R}_{4}$, позволяющий наиболее полно представить строение рифейских отложений на всей территории исследования.

Корреляция горизонта $\mathrm{R}_{4}$ основывается на совокупности имеющейся априорной геолого геофизической модели строения рифейских отложений Сибирской платформы. Фазовая корреляция отражающего горизонта $\mathrm{R}_{4}$ сложна и неоднозначна. Волны, отражённые от внутренних границ рифея, отличаются меньшей динамической выразительностью в сравнении с вышележащими отложениями венда, их выделение и прослеживание на фоне интенсивного фона волн-помех возможно только при наличии углового несогласия с границами вышележащего комплекса.

Сложность корреляции также состоит и в отсутствии единой стратификации различных фациальных зон. У многочисленных исследователей, занимающихся вопросами развития рифейских отложений, отсутствует общепринятая точка зрения на индексацию и стратиграфическую привязку внутририфейских горизонтов. На сегодняшний день имеется несколько точек зрения на сопоставление неравномерно изученных глубоким бурением отложений рифея Байкитской и Катангской НГО. Одна точка зрения сопоставляет эти разрезы как одновозрастные [Краевский, 2013 и др]. Другая предполагает надстраивание разреза Байкитской НГО над разрезом Катангской НГО [Филипцов, 2011 и др]. К сожалению, анализ сейсмических материалов на данном этапе исследования не позволяет однозначно прокоррелировать внутририфейские горизонты и, следовательно, утверждать о правомерности той или иной точки зрения.

Авторами отчета принято стратифицировать отражающий горизонт $\mathrm{R}_{4} \mathrm{c}$ низами мадринской свиты и ее стратиграфическими аналогами (кровля аянской свиты в Катангском районе; кровля стрельногорской свиты в Туруханском районе; карбонатные прослои в кварц-серицитовых сланцах средней подсвиты удерейской свиты в районе Енисейского кряжа).

По результатам работ составлена схема структурно - тектонического районирования рифейских отложений (Рис. 2).

Анализируя данную схему можно сделать вывод, что Ангаро - Котуйский прогиб в поперечном сечении имеет ассиметричное строение. Западный борт характеризуется наиболее сложным строением. Восточная часть Ангаро-Котуйского прогиба отличается более пологим примыканием отражающего горизонта $\mathrm{R}_{4}$ к отложениям венда. В южной части Ангаро Котуйского прогиба по временным разрезам наблюдается пострифейское раздвоение его осевой части, за счет появления Чадобецкого поднятия. Данные комплексных аэрогеофизических съемок подтверждают, что в пределах Ангаро - Котуйского прогиба отмечается две зоны прогибаний, разделенные осевой зоной поднятий [Буш, 2009]. Восточный борт Приенисейского прогиба характеризуется моноклинальным погружением с неравномерно нарастающей мощностью рифейских отложений. Наиболее погруженные в современном плане участки фиксируются в пределах Курейской синеклизы на севере рассматриваемой территории, на востоке зоны Ангарских складок и юго-западе Присаяно-Енисейской синеклизы. Также в рамках данной работы построена прогнозная схема довендской эрозионной поверхности на основе анализа временной мощности между отражающимих горизонтами $\mathrm{R}_{4}$ - Rо и данных по скважинам. Геологический прогноз выходов толщ рифея на довендскую поверхность может рассматриваться как схематичный. Для упрощения модели некоторые свиты рифейского интервала объединены.

\section{Благодарности}

Авторы благодарят Филипцова Юрия Алексеевича (начальника Департамента по недропользованию по Центрально-Сибирскому округу) за консультации и ценные замечания к полученным результатам. 


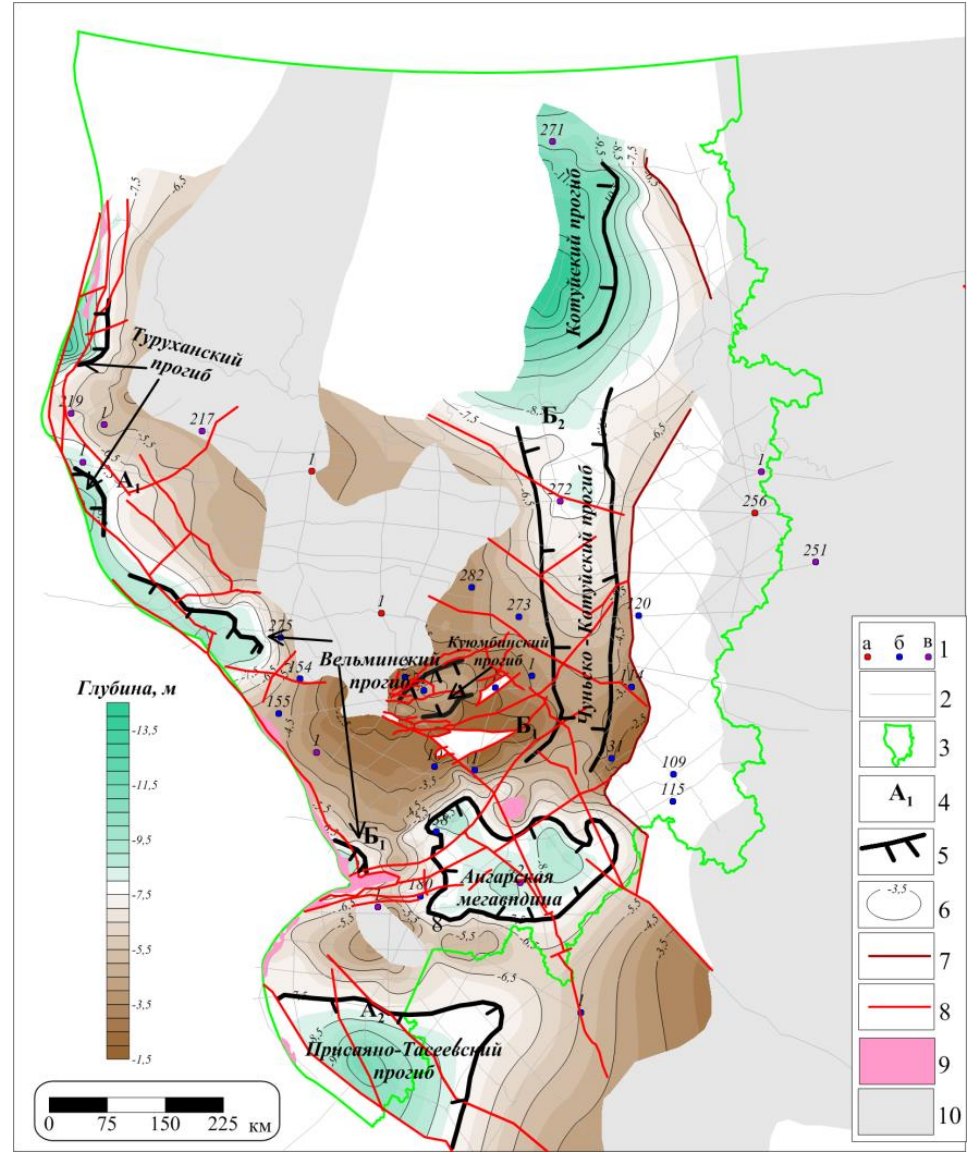

Рисунок 2 Структурно - тектоническое районирование рифейских отложений

Условные обозначения:

1 - скважины: а - вскрыла фундамент, б - вскрыла рифейские отложения, в - нет данных; 2 маршрутные профили; 3 - контур работ; 4 - "ячеи" рифейских прогибов по данным Ю.А. Филипцова; 5 структурно - тектонические элементы рифейских отложений; 6 - изолинии отражающего горизонта

$R_{4}, \kappa м$ (низы мадринской свиты и ее стратиграфических аналогов); 7 - граница выклинивания отражающего горизонта $R_{4} ; 8$ - тектонические нарушения; 9 - выходы рифейских отложений на дневную поверхность; 10 - зона отсутствия рифейских отложений

\section{Библиография}

1.Буш В.А. Строение Иркенеевско - Чадобецкого авлакогена по данным комплексных аэрогеофизических съемок. - Современные аэрогеофизические методы и технологии, 2009, вып. 1, т.1. - С.143-153

2. Ефимов А.С., Смирнов М.Ю. и др. Обобщение результатов анализа геологических и сейсмических данных в пределах Сибирской платформы на территории, обеспечивающей прирост запасов углеводородного сырья для нефтепровода "Восточная Сибирь- Тихий океан". Геология и минерально-сырьевые ресурсы Сибири, 2010. -С.12-32.

3.Краевский Б.Г. К стратиграфии рифейских отложений северо-восточной части Байкитской антеклизы //Региональная стратиграфия позднего докембрия и палеозоя Сибири Сб. науч. тр. Под редакцией В.И. Краснова. - Новосибирск: ФГУП СНИИГГиМС, 2013. С. 36-40.

4.Мельников Н.В., Якшин М.С., Шишкин Б.Б., Ефимов А.О., К Карлова Г.А., К Килина Л.И., Константинова Л.Н., Кочнев Б.Б., Краевский Б.Г., Мельников П.Н., Наговицин К.Е., Постников А.А., Рябкова Л.В., Терлеев А.А., Хабаров Е.М. Стратиграфия нефтегазоносных бассейнов Сибири. Рифей и венд Сибирской платформы и ее складчатого обрамления. Новосибирск: Академическое издательство «Гео», 2005. - 428 с.

5.Филипцов Ю.А. Нефтегазоносность верхнего протерозоя Западной части Сибирской платформы - Диссертация на соискание ученой степени доктора геолого-минералогических наук. - Новосибирск. - 2015. - 411 с. 


\section{EAGE}

\section{References}

1.Bush VA The structure of the Irkeneevsko-Chadobetskii avlakogene according to complex aerogeophysical surveys. - Modern aerogeophysical methods and technologies, 2009, no. 1, v.1. P.143-153

2. Efimov AS, Smirnov M.Yu. Etc. Generalization of the results of the analysis of geological and seismic data within the Siberian Platform on the territory ensuring the growth of hydrocarbon raw material reserves for the oil pipeline "Eastern Siberia-Pacific Ocean". -Geology and mineral resources of Siberia, 2010.-C.12-32.

3.Kraevsky BG Towards the stratigraphy of Riphean deposits of the northeastern part of the Baikite anteclise. // Regional stratigraphy of the Late Precambrian and Paleozoic of Siberia. Sci. Tr. Edited by V.I. Krasnov. - Novosibirsk: FGUP SNIIGGiMS, 2013. P. 36-40.

4. Melnikov NV, Yakshin MS, Shishkin BB, Efimov AO, Karlova GA, Kilina LI, Konstantinova LN, Kochnev BB, Kraevsky BG, Melnikov PN, Nagovitsin KE, Postnikov AA, Ryabkova LV, Terleev AA, Khabarov Ye.M. Stratigraphy of oil and gas bearing basins of Siberia. Riphean and Vendian of the Siberian Platform and Its Folded Framing [Text] - Novosibirsk: Academic Publishing House "Geo", 2005. - 428 p.

5. Filippov Yu.A. Oil and gas potential of the Upper Proterozoic of the Western part of the Siberian Platform - Thesis for the degree of Doctor of Geological and Mineralogical Sciences. - Novosibirsk. 2015. - $411 \mathrm{p}$. 